\section{Mummy Wheat}

Popular belief in the viability of wheat grains which have been interred in ancient tombs, sometimes thousands of years old, has during the past few years been severely shaken by morphological and physiological tests on genuine mummy wheat, and also by bringing into question the authenticity of other so-called specimens. But in many people's minds, the possibility of mummy wheat being viable seems still to exist. A survey of this subject was given in Nature of May 2, 1931, p. 675, where genuine mummy wheat and the more questionable cases were discussed. In NATuRE of August 19, 1933, p. 271, an example of some so-called mummy wheat from an Indian tomb was shown to be actually a recent one, the whole idea having been based, at the best, on a misunderstanding. The possibility of the inordinate longevity of some seeds clearly never fails to appeal to the imagination. An article reviewing work on this subject appeared in NATURE of September 23, 1933, p. 469 . On September 6 last, Sir E. A. Wallis Budge offered, through the medium of the Times, to supply samples of wheat obtained from a nineteenth dynasty tomb in Western Thebes, to responsible institutions in order that the germinating capacity of these seeds could be tested. Although the results of all such tests have not been announced so far, attention should be directed to a report by Mr. W. H. Parker, director of the National Institute of Agricultural Botany, Cambridge, which appeared in the Times of October 29. After subjecting the seeds to strictly controlled germination tests, every grain had completely decayed within sixteen days, and had become attacked by a growth of mould. Morphological examination of the embryos before the tests had also indicated that the sample was incapable of germination.

\section{Early Man in East Africa: Further Investigation}

NotwithstaNDING the close and expert scrutiny to which Dr. L. S. B. Leakey's evidence for the early occurrence of man in Kenya has been subjected, the far-reaching effect of the conclusions to which it leads make it eminently desirable that no means of verifying and substantiating the data should be neglected. The geological evidence of deposits in Kenya, where volcanic action has been marked, has proved notoriously difficult of interpretation; and the announcement is, therefore, welcome that Prof. P. G. H. Boswell, of the Imperial College of Science, whose views on the interpretation of deposits with which relics of early man are likely to be associated carry considerable weight, is to proceed to Kenya for the purpose of investigating with Dr. Leakey the conditions of the discovery of relies of early man in East Africa. Prof. Boswell will leave London during the current month and he and Dr. Leakey will be joined in Kenya by Mr. E. J. Wayland, director of the Geological Survey of Uganda, who is at present home on leave. Mr. Wayland's extensive studies of the prehistory of man in Uganda, as well as his knowledge of geological conditions in Kenya and Tanganyika, will be of invaluable assistance in arriving at what, it may be hoped, will be final and decisive verdicts on the important questions which have given rise to controversy.

\section{Samaria}

THE article contributed to the Times of November 3 by Mr. J. W. Crowfoot, in connexion with the exhibition illustrating the excavations of Samaria now open at the rooms of the Palestine Exploration Fund at 2 Hinde Street, London, W., gives a very informative view of the general results which have been achieved by recent work on the site of the city of Ahab. It is evident that the joint expedition, for which Harvard University, the Palestine Exploration Fund and other bodies are responsible, has not only added a great deal to the map of ancient Samaria, as Mr. Crowfoot says, but it has also reached a most important phase in its undertaking in the proposed extension of the investigation on the north side of the site, where it is possible that the principal gate of the city may lie. The superior character of the stone work of the Israelitish levels was already known from the work carried out by the expedition of Harvard University in pre-War days. This skill in the construction of fortifications is confirmed by the discovery of the remarkable bastion to which Mr. Crowfoot refers. Even more suggestive of the influences at work in the northern kingdom are the remarkable ivories which have been discovered and are regarded as a corroboration of the reference by the prophet Amos to the "ivory couches" of Samaria, which these remains of plaques and other carvings once adorned. It may be trusted that the reference by Mr. Crowfoot to the dependence of the projected excavation on the provision of funds is a reminder rather than a warning.

\section{Ancient Monuments in Cyprus}

The address on the "Ancient Monuments of Cyprus", delivered by Sir Charles Peers at the meeting of the Royal Empire Society on November 5, afforded ample justification-if justification were needed-for the appeal issued in the spring of this year by the influential Cyprus Committee, of which Lord Mersey is chairman, for funds for the preservation of these monuments. Sir Charles, as the result of a visit of inspection to the island, on which he was accompanied by Sir George Hill, director of the British Museum, was in a position to assure his audience, and through them, a wider public, of the unique character and exceptional interest of the long series of monuments, many of them of surpassing beauty, which extends from prehistoric times to the Turkish occupation. To the archæologist the island of Cyprus, which gave its name to the metal first put to practical uses by men, and which was a meeting place of the cultures of the Mediterranean, of Egypt, and of Asia, is a source of the material of prehistory of which the potentialities have yet to be explored systematically; while the historian and the student of art may here view within its restricted compass a sequence of Phœnician, Greek, Roman, Byzantine, Gothic, Renaissance and Turkish, scarcely surpassed, 